\title{
GREEN INDEXING OF HISAR MUNICIPAL CORPORATION USING GEOSPATIAL TECHNIQUES
}

\author{
D. Singh ${ }^{1 *}$, S. Mondal ${ }^{2}$, R.S. Hooda ${ }^{1}$ \\ ${ }^{1}$ Haryana Space Applications Centre, CCS HAU Campus, Hisar Haryana-125004, dsbaghel01@gmail.com \\ ${ }^{2}$ Institute of Environment Education and Research, Bharati Vidyapeeth (Deemed to be University)
}

Commission V, SS: Infrastructure and Development Planning

KEY WORDS: Green Space, Green Index, LISS-IV, SVM, MRS

\begin{abstract}
:
Urban Green Space (UGS) enhances the structure of the landscape of a city. It provides economic, social and health benefits to the inhabitants. Rapid urbanization and increase in population has put extreme pressure on urban green spaces. Therefore, mapping of urban green spaces is important to facilitate the urban planning sustainably. This study has been taken up to map the UGS in the Hisar Municipal Corporation (HMC) area of Haryana State constituting an area of 4197.32 ha using high resolution LISS-IV data of November, 2017. Three different methods namely (a) Onscreen Digitization (b) Support Vector Machine-based classification (SVM) and (c) Multi Resolution Segmentation (MRS) have been tested to extract the green spaces. The onscreen digitization method has been considered as best method as compared to SVM and MRS because of the intervention of human mind and full control on manual editing. The SVM under estimated the green space for HMC with average relative deviation of $15 \%$. However, it extracted the green area precisely without mixing of open spaces. MRS have given good results in terms of total area (relative deviation was 5\%), however, spatial distribution of green spaces have been mixed with open spaces. The study identified the green index of HMC and suggested the suitability and sustainability of the city based on World Health Organization (WHO) defined standards. Green space for Hisar Municipal Corporation was 1690.96 ha with average urban green space index of 0.40 . Per capita green cover for $\mathrm{HMC}$ was $9.69 \mathrm{~m}^{2} / \mathrm{inhabitant}$, which is as per the standard reported by WHO i.e. $9 \mathrm{~m}^{2} /$ inhabitant. Further study may suggest some other algorithm for better results and automatic green space extraction.
\end{abstract}

Keywords: Green Space, Green Index, LISS-IV, SVM, MRS

\section{INTRODUCTION}

Urban green space is considered as an important element in an urban setting (Kabisch and Haase, 2014; Hansen et al. 2015; Aronson et al. 2017). Urban green space broadly define the green space as an public open space or an undeveloped land with natural vegetation that includes the parks, forests, green roofs, streams and river banks or wetland, community gardens, street trees and natural conventional area as well as less conventional space such as green walls, green alleyways and cemeteries. It may also include private green space such as private backyards, communal grounds of apartment building and corporate campuses (Cilliers et al. 2013; Wolch et al. 2014).Urban green space not only avail with provision of critical ecosystem services, environmental and health benefits to the city dwellers but it also add value to the socio-cultural space and economic purpose (Kabisch and Haase, 2014; Gunnarsson et al. 2017). Green space at urban setting is considered as the lungs of the city (ThiLoi et al 2015). It enhances the public health and also fulfils a wide range of different roles, such as it provide areas for recreation purposes. It maintains and increase property values through their aesthetic characteristics and functionality (Aronson et al. 2017; Lee et al. 2017).

Furthermore the quality of urban environment and presence of vegetation plays a major role in many aspect of climatic modification such as regulation of temperature extremes, reduction of wind velocity, reduction of pollutants, mitigation of the urban heat island effect, maintenance of ecological balance, protection of biodiversity, promotion of the quality of life and environmental-gentrification (Aronson et al. 2017; Gunnarsson et al. 2017; Lee et al. 2017; Hwang et al., 2018; Rupprecht and Byrne, 2018) Over all urban green space contributes to the sustainable development of the urban ecosystem (Xu et al. 2018).

Rapid urbanization and the human activity has highly modified and transformed the urban environment, landscape heterogeneity, function and its uses (Vitousek et al. 1997; Song et al. 2017; Xu et al. 2018). The existence of the green space in an urban fabric or within a city is therefore complex to study and liable to degrade with high rate. This has led to loss of urban green cover that has not only threatens the urban climate and the ecosystems, but

*Corresponding Author 
has also effected the city's image and the residential satisfaction (Wolch et al. 2014; Xu et al. 2018). The maintenance and development of urban vegetative area and its sustainable growth due to the fast growing cities is a major challenge for many countries (Xu et al. 2018). Therefore to achieve sustainable urban development, creation and protection of green space is utmost important. This can be accomplished through mapping and strategic planning of the urban green space (Aronson et al. 2017).

Taking the importance of urban green space in to account present study aims to map the urban green space using Linear Imaging Self Scanning (LISS-IV) data from Resourcesat satellite with spatial resolution of $5.8 \mathrm{~m}$. Three different classification methods, includes one manual i.e. onscreen digitization and two automatic i.e. SVM and MRS were used for extracting urban green space. The study addressed the problem of extraction of green space through satellite imagery and suggested more research in identifying the possible method of green space extraction. It has further estimated the green health of the city in terms of green index value and per capita green space. Finally the output of per capita green space was compared with international guideline given by World Health Organization (WHO) and suggested the sustainability and suitability of the HMC.

\section{MATERIALS AND METHODOLOGY}

\subsection{Study Area}

HMC is situated in the Hisar district of the Haryana State (Figure 1) and about $167 \mathrm{Km}$ away from national capital city, New Delhi. Geographically it is in south-western part of the state and in the central part of the Hisar district. The $\mathrm{HMC}$ is bounded in between the latitude of $29^{\circ} 6^{\prime} 8.868^{\prime \prime} \mathrm{N}$ to $29^{\circ} 10^{\prime} 58.654^{\prime \prime} \mathrm{N}$ and longitude of $75^{\circ} 41^{\prime} 14.362^{\prime \prime} \mathrm{E}$ to $75^{\circ} 46^{\prime} 59.581 "$ E. It covers a total area of approximately 4197.32 ha. As per census 2011 the total population of the $\mathrm{HMC}$ is 307024 . HMC experiences a sub-tropical climate. The temperature may rise up to $48^{\circ} \mathrm{C}$ and lower down to $0^{\circ} \mathrm{C}$.

It has four seasons namely Monsoon, Post-Monsoon, Winter and Summer (Krishnan \& Bhatia, 2013). The average annual rainfall of the HMC is $330 \mathrm{~mm}$. The natural vegetations of are the grasses, such as "Dhaman" (Cenchrus spp.) used as fodder for cattle space \& dense forest patches. The most commonly occurring bush is the Jhar beri (Ziziphus rotundifolia). There are Shisham (Delbergia Sisseo), mostly occurs in the canal bank and road side in the district (District gazetteer Hisar, 1987). Trees of Azadirachta indica (Neem) and Eucalyptus are also found along the roadside.

\subsection{Material and Method:}

The methodology adopted for extraction of the green space in urban area and map the availability of green space involves the digitization of green features on a scale of 1:3000 of Resourcesat2 (LISS-IV) image in ArcGIS 10.5, supervised classification of Resourcesat2 (LISS-IV) through support vector machine in ENVI 4.4 and multi resolution segmentation in eCognition Developer 64. The output obtained were further analysed in GIS to calculate per capita green space and urban green health index.

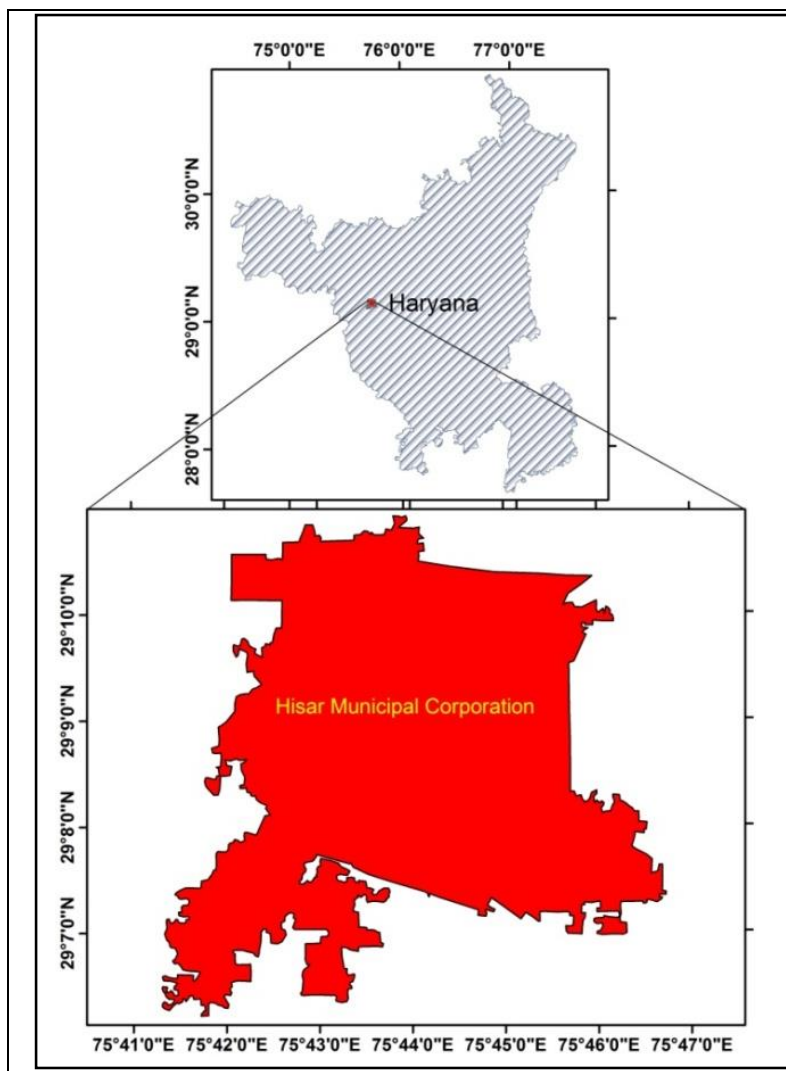

Figure 1: Study Area showing Hisar Municipal Corporation boundary and its location in Haryana

\subsubsection{Data Use}

To compute the urban green parameter IRS-P6 LISS IV satellite imagery with band resolution $5.8 \mathrm{~m}$ were used. IRS-P6LISS IV includes multispectral camera operating in three spectral bands i.e. Green, Red and NIR (Table 1). Municipal boundary of HMC was obtained from Haryana Space Application Centre (HARSAC) which is a nodal agency of remote sensing and geographic Information System (GIS) and used for the analysis of green space inside the boundary (Table 1).

\begin{tabular}{|c|c|c|c|c|}
\hline $\begin{array}{l}\text { Sl. } \\
\text { No. }\end{array}$ & $\begin{array}{l}\text { Data } \\
\text { Used }\end{array}$ & $\begin{array}{l}\text { Band (spectral } \\
\text { range in } \mu \mathrm{m} \text { ) }\end{array}$ & $\begin{array}{l}\text { Spatial } \\
\text { Resoluti } \\
\text { on }\end{array}$ & $\begin{array}{l}\text { Swath and } \\
\text { Radiometry }\end{array}$ \\
\hline 1 & $\begin{array}{l}\frac{\text { LISS }}{\text {-IV- }} \\
\frac{\text { Nov. }}{2017} \\
\underline{2017}\end{array}$ & $\begin{array}{l}\text { 1. Green }(0.52- \\
0.59) \\
\text { 2. Red }(0.62- \\
0.68) \\
\text { 3. Near Infra Red } \\
(0.77-0.86)\end{array}$ & $5.8 \mathrm{~m}$ & $\begin{array}{l}23.9 \\
\mathrm{Km} / 10 \text {-bit }\end{array}$ \\
\hline
\end{tabular}

Table 1. Specification of data used in this study

The paradigm of methodology used in this study is represented in Figure 2. Ground truth data was collected 
using handheld GPS (Garmin-72) during November 2017 which was further incorporated into classification and extraction procedure for better accuracy.

\subsubsection{Method}

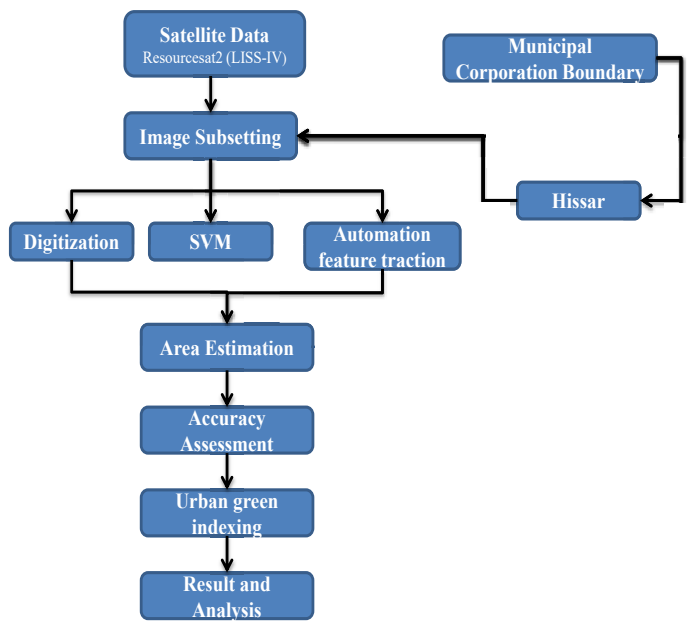

Figure 2. Paradigm of the methodology applied for the study

\subsubsection{Data Processing and onscreen digitization of green space}

Data set received in ready to use format from National Remote Sensing Centre (NRSC), Hyderabad. The individual bands i.e. Green, Red and NIR were then stacked. The layer stacked image was transformed into projected coordinate system i.e. UTM, WGS-84, Zone N43. Finally the images were mosaicked and area of interest i.e. HMC was extracted using HMC boundary. Onscreen digitization of green spaces, open space and other land use was done in ArcGIS 10.5 software environment. A vector map of green space was prepared based on tone, texture and pattern of the image. The extraction method followed by digitization of green space on the scale of $1: 3000$. We have visually evaluated the land feature and generated attributes for describing the areas forming the part of green space. After that the accuracy was assessed using relative deviation (RD) method where the area obtained from SVM and MRS for individual polygons were compared with the area of same polygon from onscreen digitization. The basic type of urban green classes includes forest, trees/high urban vegetation, park and garden, grass or low vegetation, open space with vegetation or vegetation nearby the water areas.

\subsubsection{Green space mapping through SVM}

Further Supervise classification technique, SVM were followed to map the green spaces along with other land uses in ENVI 4.4 software environment. Support vector machine as a tool were implement to automatically extract the landuse and land cover features. A set of training samples is assigned to determine the green space and other land use categories. A number of land use land cover classes were prepared that consist of vegetation, built up, open space water bodies and agriculture.

Application of SVM algorithm separates the image into different classes. It identify the class associated with each pixel and separate the classes with a decision surface that maximises the margin between the classes. These surface is called as hyperplane and the data point closest to the hyperplane called as support vectors. The support vectors are the elements of training set. SVM is a non-parametric statistical learning algorithm that aims to create binary classification for each possible pair of classes. The classification within SVM is performed using various type of kernels which turns nonlinear boundaries into linear ones in the high dimensional space to define optimal hyperplane. ENVI's implementation of SVM is based on pairwise multi class classification strategy. Classification output values of each pixel received is used for probability estimation, stored in ENVI as rule images, and represent the true probability that range between 0 to 1 , i.e. sum of values of each pixel is equal 1. Classification is performed by selecting the highest probability. An optional threshold allows to report the pixel with probability value less than the threshold as unclassified. The ENVI SVM classifier operate four types of kernels: linear, polynomial, radial basis function kernel (RBF) and sigmoid. The result is obtained through Radial basis function kernel in this study. The mathematical representation of each kernel is as follows;

Linear $K(x i, x j)=x i T x j$

Polynomial $K(x i, x j)=($ gxiTxj $+r) d, g>0$

RBF $K(x i, x j)=\exp (-g\|x i-x j\| 2), g>0$

Sigmoid K $(x i, x j)=\tanh ($ gxiTxj $+r)$

Where:

$\mathrm{g}$ is the gamma term in the kernel function for all kernel types except linear,

$\mathrm{d}$ is the polynomial degree term in the kernel function for the polynomial kernel,

$\mathrm{r}$ is the bias term in the kernel function for the polynomial and sigmoid kernels,

$\mathrm{g}, \mathrm{d}$, and $\mathrm{r}$ are user-controlled parameters, as their correct definition significantly increases the accuracy of the SVM solution.

2.2.5 Green Space mapping through Object based classification technique

Object based classification technique to automatically extract the green space was further applied to extract green space. Trimble ${ }^{\circledR}$ eCognition Developer64 software was used to run MRS algorithm with the input values as Scale Parameter: 10, shape: 0.1 , compactness: 0.5 . The image segmentation algorithm that includes the MRS is controlled by three main factors: 1 . The scale parameter (SP) that determine the maximum allowed heterogeneity for the resulting segments 2 . The weight of colour and shape criteria in the segmentation process (shape) and 3. The 
weight of the compactness and smoothness criteria (Compactness).

MRS is a bottom-up segmentation algorithm that is considered as a pair-wise region merging technique where each pixel consecutively merged to form a new image object. MRS is an optimization procedure which, for a given number of image objects, minimizes the average heterogeneity and maximizes their respective homogeneity for a give resolution of image object. This homogeneity criterion is defined as a combination of spectral homogeneity and shape homogeneity that influence calculation by modifying the scale parameter. Higher values for the scale parameter result in larger image objects, smaller values in smaller image objects. Each image object uses the homogeneity criterion to determine the best neighbor to merge with. The procedure continues to merge with another image object best neighbor and iterates until no further image object mergers can be realized without violating the maximum allowed homogeneity of an image object.

The objects iterate starting with individual pixels that are grouped until the threshold representing the upper object variance is reached. The variance threshold is considered as scale parameter that is one of the important criteria that defines the maximum standard deviation of the homogeneity criteria in regard to the weighted image layer and determines the maximum allowed heterogeneity for the resulting image object. For heterogeneous data, the resulting objects for a given scale parameter will be smaller than in more homogeneous data. Scale Parameter value can be modified to adjust the varying size of image objects based on 4 criteria i.e. colour, shape, smoothness and compactness. With this parameter setting an image is merge with a better degree of fitting and said to fulfill the homogeneity criterion. For green space an important parameter i.e. Normalized Difference Vegetation Index (NDVI) were used which was quantified as given in equation 1.

$$
N D V I=\frac{\rho N I R-\rho R E D}{\rho N I R+\rho R E D} \quad \text { eq. } 1 \ldots \text { (Rouse et al., 1973) }
$$

Where

$\rho N I R=$ The Near-infrared Channel (NIR-Band) $\rho R E D=$ Red Channel (Red-Band)

NDVI generates pixel values range from -1 to +1 . Green vegetation gives positive NDVI. Values close to $+1(0.8-$ $0.9)$ represents highest possible vegetation density.

\subsubsection{Urban Green Space Index}

Urban green space is a crucial evaluation standard for urban landscape planning. Urban green space is defined as the ratio of total green space and total area where the green space is distributed. This can be represented by formula given in equation 2. Current analyses have been done in $100 \times 100 \mathrm{~m}$ grid coded in specific regions based on continuous patch of the green cover.
Urban Green Space Index $=\frac{\text { Green area of a region }}{\text { Total land area of that region }}$

eq. 2... (Liu et al., 2015)

\subsubsection{Green Space Per-capita}

Per capita green space is a crucial evaluation for the harmony of urban development and land scape construction. It is defined the as the ratio of total green space in an area and total population of that area. It may be represented by equation 3 .

Per Capita Urban Green Space $=\frac{\text { Green Space Area in a region }}{\text { Total population of that region }}$ eq.3... (Senanayake et al. 2013)

\section{RESULTS AND DISCUSSION}

\subsection{LULC of HMC}

Urban green space was digitised along with other land use classes including agriculture, built-up, water body, open space, and wetland. The land use and land cover features are estimated to show the area occupied by each land feature. The area for each class was measured in ha. The figure given below (Figure 4) represents the HMC. The area statistics of LULC showed a total of 2178.49 ha area of the HMC which is approximately $51 \%$ of the total area of HMC is covered under built-up class.

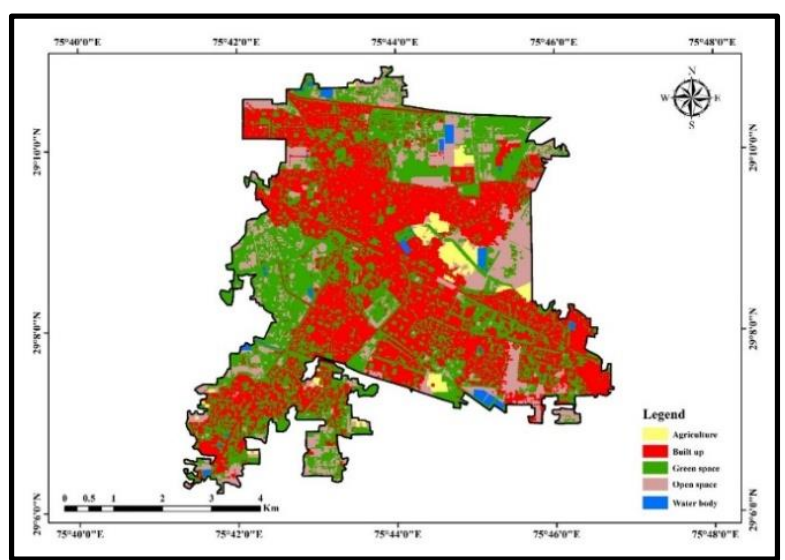

Figure 3. LULC including green space Map of HMC

The coverage of agriculture is $2.49 \%$ of the total geographical area. $30.50 \%$ area is under green space. Open space is covering a total of $13.87 \%$ area of the total geographical area of HMC. However the total area of aerial water coverage is $1.23 \%$ (Table 2).

\begin{tabular}{|l|r|r|}
\hline Class & \multicolumn{1}{|l|}{ Area (ha) } & \multicolumn{2}{|l|}{ Percentage } \\
\hline Agriculture & 104.66 & 2.49 \\
\hline Built-up & 2178.49 & 51.90 \\
\hline Green Space & 1280.31 & 30.50 \\
\hline Open Space & 582.08 & 13.87 \\
\hline Water Body & 51.78 & 1.23 \\
\hline Total & $\mathbf{4 1 9 7 . 3 2}$ & $\mathbf{1 0 0 . 0 0}$ \\
\hline
\end{tabular}

Table 2: Area of LULC for the HMC 


\subsection{Comparison of Different Methods for Urban Green Space mapping}

Three methods namely onscreen digitization, SVM machine learning and MRS automatic feature extraction method were compared for their potential in urban green space extraction. From the results of onscreen digitization it was observed that the Hisar is green (Figure 4) with a total green cover of 1690.96 ha covering $40.30 \%$ to its total geographical area (Table 3). At the same time SVM have given a total green space area of 1138.05 ha which is very less as compared to onscreen digitisation based green space (Figure 5). MRS has shown a close statistic of green space with a total area of 1571.11 ha (Table 3 and Figure 6). This was near to the onscreen digitisation based green space.

The agriculture present inside the HMC boundary were also included in the green pace as suggest by Van Leeuwen et al., 2010 and Thierfelder and kabisch, 2016. The results showed that the MRS automatic feature extraction method is accurate as it was giving the green space area similar to onscreen digitisation method which was considered as the most accurate method. However, the mixing of open spaces in the green space was also observed. This is due to the threshold of patch size given in MRS based green space extraction. The SVM based green space area was much less as compared to green space area obtained by onscreen digitisation. This was because of the identification and classification of individual pixels without greenery present within a big patch of the green cover in to open space. It was also observed that the green space mapped by SVM was accurate for very small patches (parks) present in a dense urban setup.

Since the SVM takes spectral signature of green vegetation only into account for the classification of green space, the phenological stage of vegetation may be another important factor for less area mapped. It means the chances of inaccuracy due to patches having leaf less vegetation may not be classified as green space and will remain unclassified. Thus it is very important to select a month in which no vegetation is in leaf less condition if the SVM is to be utilized for green space mapping.

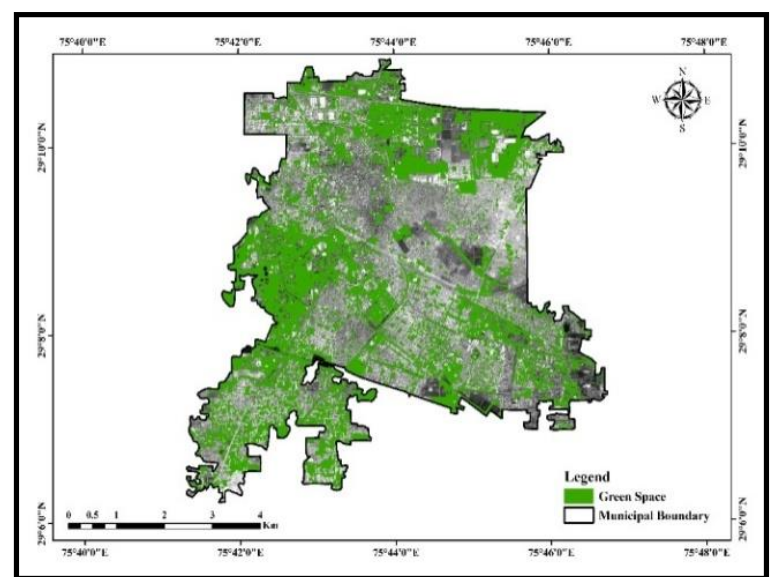

Figure 4. Green Space obtained by on screen digitization

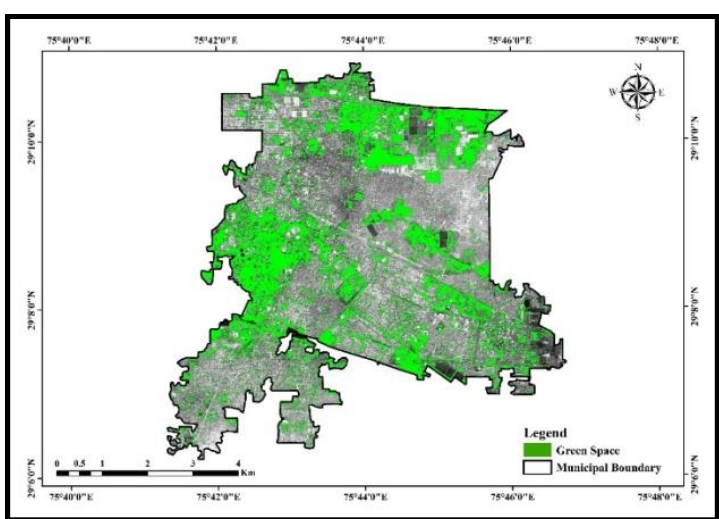

Figure 5. Green Space obtained by SVM

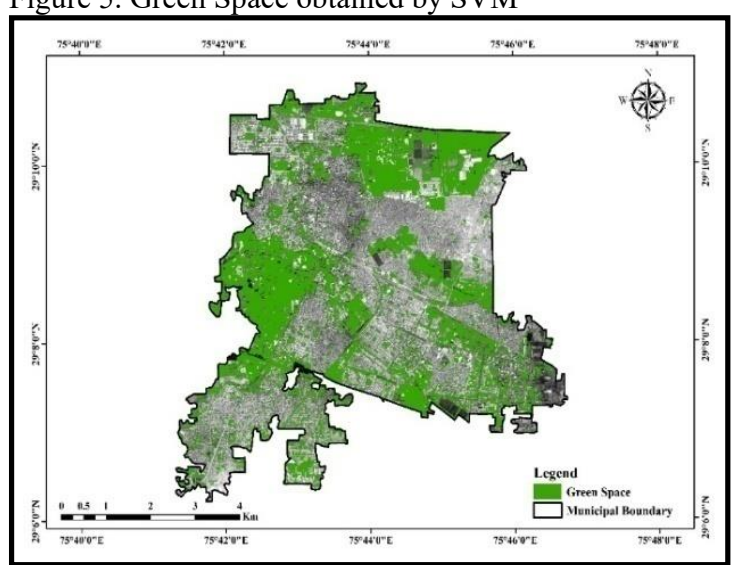

Figure 6. Green Space obtained by MRS

Further the onscreen digitization is a time taking process and inclusion of automatic MRS method is having limitation of mixing of open spaces in to green space. Thus the SVM which was accurately mapping the green spaces in terms of its spatial distribution may be taken for the purpose of extraction of green spaces using satellite data of an appropriate month of the year.

\begin{tabular}{|l|l|}
\hline Method & Area (ha) \\
\hline Digitization & 1690.96 \\
\hline SVM & 1138.05 \\
\hline Automatic & 1571.11 \\
\hline
\end{tabular}

Table 3. Area statistics of green space from three different methods

\subsection{Accuracy Assessment}

It was observed that the relative deviation (RD) in the area of polygon was ranging from $20.54 \%$ to $-6.24 \%$ with average $15 \%$ for SVM. The RD for MRS was 16.75 to $1.23 \%$ with average value of $5.45 \%$ (Figure 7 ).

\subsection{Green Health Indexing (GHI)}

The GHI was done for understanding the green health of the HMC. The green index is represented in Table 4. It was 
observed that the average GHI was 0.40 for the study area showing $40 \%$ of the geographical area of HMC is covered under the vegetation. GHI from SVM was 0.35 and from MRS was 0.37 .

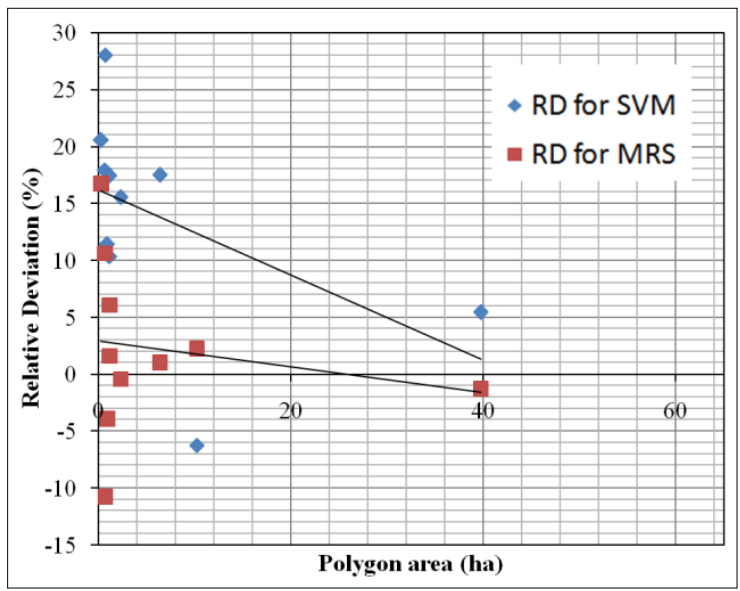

Figure 7: Relative Deviation in area from SVM and MRS

Grid-wise analysis showed variations in GHI values 0.0 to 1 (Figure 8). The value 1 in GHI represents that the whole grid is covered by green space. The coverage of green space continuously decreasing in grid with decrease in GHI value till it approached towards nil. The less GHI from SVM and MRS is due to less mapped area of green cover by both these methods. However, the GHI is showing high value for the HMC. The main reason for this is the green university campus of Chaudhary Charan Singh (CCS), Haryana Agricultural University (HAU) which covers 2921.43 ha of HMC.

This is approximately $70 \%$ of the total geographical area of HMC. The campus has farm fields, big patches of trees and ornamental gardens. The proper management of green cover inside the University campus maintains the greenery of vegetation present. These were detected properly by SVM algorithm.

\begin{tabular}{|c|c|c|c|}
\hline \multirow{2}{*}{ Area of HMC } & \multicolumn{3}{|c|}{ GHI or Urban green Index } \\
\cline { 2 - 4 } & Digitization & SVM & MRS \\
\hline 4197.32 & 0.40 & 0.35 & 0.37 \\
\hline
\end{tabular}

Table 4: Urban green Index for different Municipal Corporations taken in this study

\subsection{Per-Capita Green Cover}

Per capita green space for HMC is represented in (Table 5). Per-capita green space was $9.70 \mathrm{~m}^{2} /$ inhabitant after including agricultural portion. Per capita green space is estimated from WHO standard reported $9.5 \mathrm{~m}^{2} /$ inhabitants.

\begin{tabular}{|l|l|}
\hline Municipal Corporation & $\begin{array}{l}\text { Per-Capita Green Space } \\
\left(\mathbf{m}^{\mathbf{2}} \text { /inhabitant }\right)\end{array}$ \\
\hline Hisar & 9.70 \\
\hline
\end{tabular}

Table 5: Per-capita green space for different Municipal Corporation

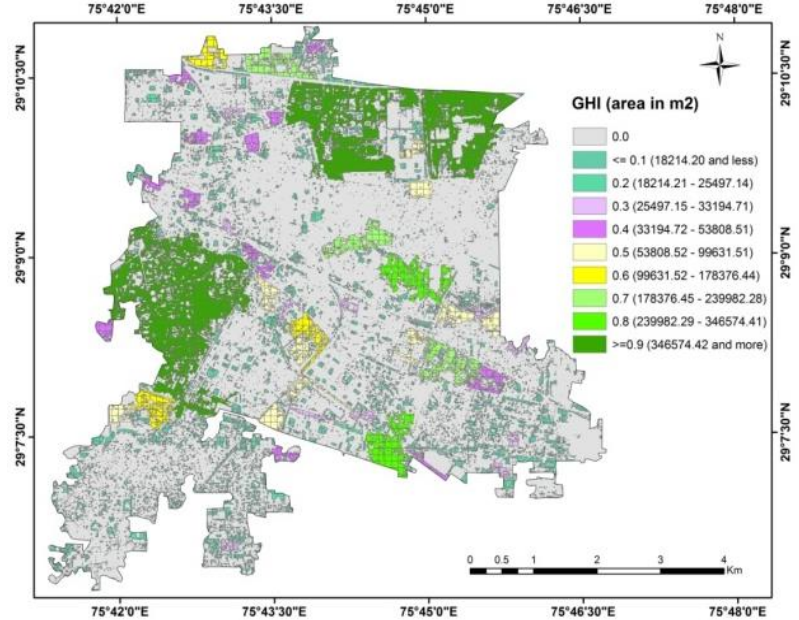

Figure 8. Green Health Index

\section{CONCLUSIONS}

The study analysed extraction of green space through on screen digitization, automatic feature extraction and machine learning method. The onscreen digitization is a tedious and cumbersome process and time consuming too, which compel many researcher to go for some appropriate method for automatic extraction of green spaces. Based on study following conclusion have been driven:

- It was identified that some of the feature in image elements i.e. pixels are unidentifiable though with high zooming scale (1:3000) during onscreen digitization. Whereas the SVM method was able to identify and classify these pixel.

- eCognition is fast process for feature extraction where the rule set has to be determined appropriately. eCognition provides the result based on scale parameter and segments and they must be defined carefully. The NDVI threshold determines the result and thus it is mandatory to define an appropriate threshold after careful investigation and research. More work is required to address these problems. However it can be concluded that none of the method is highly accurate and provide exact result in comparison to manual method i.e. on screen digitization. More study is required to identify the best possible method for automatic green space extraction.

- Digitization is best in some place while SVM and eCognition method is found to be suitable for some other place. For example the SVM may be good for city centres where the agriculture patches are absent and small patches of green space in the form of Community Park are present.

- The average GHI was found appropriate as per the guideline of WHO i.e. $9.5 \mathrm{~m}^{2} /$ inhabitants i.e. 9.70 $\mathrm{m}^{2}$ /inhabitants. However a grid based analysis is further required for better planning of urban green space at spatial scale. 


\section{ACKNOWLEDGEMENTS}

Authors are thankful to HARSAC for providing high resolution LISS-IV satellite data and HMC boundary for this research work.

\section{REFERENCES}

Aronson, M.F., Lepczyk, C.A., Evans, K.L., Goddard, M.A., Lerman, S.B., MacIvor, J.S., ... and Vargo, T., 2017. Biodiversity in the city: key challenges for urban green space management. Frontiers in Ecology and the Environment, 15(4), 189-196.

Cilliers, S., Cilliers, J., Lubbe, R., and Siebert, S., 2013. Ecosystem services of urban green spaces in African countries - perspectives and challenges. Urban Ecosyst 16: 681-702.

Gunnarsson, B., Knez, I., Hedblom, M., and Sang, Å.O., 2017. Effects of biodiversity and environment-related attitude on perception of urban green space. Urban Ecosystems, 20(1), 37-49.

Hansen, R., Frantzeskaki, N., McPhearson, T., et al., 2015. The uptake of the ecosystem services concept in planning discourses of European and American cities. Ecosyst Serv 12: $228-46$

Hwang, Y.H., Lum, Q.J.G., and Lim, L.X.C., 2018. Cooling with Green Infrastructures: The Influence of Trees on Thermal Conditions in Tropical Urban Parks. In Designing Cooler Cities (pp. 69-83). Palgrave Macmillan, Singapore.

Kabisch, N., and Haase, D., 2014. Green justice or just green? Provision of urban green spaces in Berlin, Germany. Landscape Urban Plann. 122, 129-139.

Krishnan, R.G., and Bhatia, A.K., 2013. Ground Water Information Booklet Hisar District, Haryana, Government of India Ministry of Water Resources Central Ground Water Board North Western Region Chandigarh, available online at http://cgwb.gov.in/District_Profile/Haryana/His sar.pdf.

Lee, S.J., Longcore, T., Rich, C., and Wilson, J.P., 2017. Increased home size and hardscape decreases urban forest cover in Los Angeles County's single-family residential neighborhoods. Urban Forestry \& Urban Greening, 24, 222-235.

Liu, Y., Meng, Q., Zhang, J., Zhang, L., Jancso, T., and Vatseva, R., 2015. An effective Building Neighborhood Green Index model for measuring urban green space. International Journal of Digital Earth, DOI: 10.1080/17538947.2015.1037870.

Rouse, J., Haas, R., Schell, J. and Deering, D., 1973. Monitoring vegetation systems in the great llains with ERTS Third ERTS Symposium NASA (United States, 10 14 December 1993) pp 309-317.

Rupprecht, C.D.D. and Byrne, J.A., 2018. Informal urban green space as anti-gentrification strategy? Book chapter, "just green enough", pp.1-20.
Senanayake, I.P., Welivitiya, W.D.D.P., and Nadeeka, P.M., 2013. Assessment of green space requirement and site analysis in colombo, Sri Lanka - a remote sensing and GIS approach. In: Proceedings of the International Conference on Interdisciplinary Applications of Remote Sensing and Geographic Information Systems, Mumbai, India, April, 2013.

Song, X., Huang, Y., Fu, J., Jiang, D., and Tian, G., 2017. Spatial variability and ecological effects of anthropogenic activities in a nature reserve: A case study in the Baijitan National Nature Reserve, China. Sustainability, 9(2), 239.

Thierfelder, H., and Kabisch, N., (2016). Viewpoint berlin: strategic urban development in Berlin challenges for future urban green space development. Environ. Sci. Policy 62, $120-122$.

ThiLoi, D., Tuan, P.A., and Gupta, K., 2015. Development of an Index for Assessment of Urban Green Spacesat City Level. International Journal OfRemote Sensing Applications, 5(1), 78.

Van Leeuwen, E,, Nijkamp, P., and De Noronha-Vaz, T., 2010. The multifunctional use of urban green space. Int. J. Agric. Sustain, 8 (1-2), 20-25.

Vitousek, P.M., Mooney, H.A. Lubchenco, J., and Melillo, J., 1997. Human domination of Earth's ecosystems. Science, 277, 494-499.

Wolch, J.R., Byrne, J. and Newell, J.P., 2014. Urban green space, public health, and environmental justice: The challenge of making cities 'just green enough'. Landscape and Urban Planning, 125, 234-244.

Xu, C., Haase, D., Pribadi, D.O., and Pauleit, S., 2018. Spatial variation of green space equity and its relation with urban dynamics: A case study in the region of Munich. Ecological Indicators, 93, 512-523. 